\title{
Photon Attenuation Coefficients of Iron Doped Clay at $662 \mathrm{keV}$
}

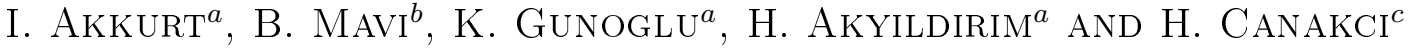 \\ ${ }^{a}$ Department of Physics, Art and Science Faculty, Suleyman Demirel University, Isparta, Turkey \\ ${ }^{b}$ Department of Physics, Art and Science Faculty, Amasya University, Amasya, Turkey \\ ${ }^{c}$ Department of Civil Engineering, Gaziantep University, Gaziantep, Turkey
}

\begin{abstract}
After discovery of the radioactivity by Becquerel, radiation started to be used in large fields and it became part of our life nowadays. Using radiation from industry to medicine brings its hazardous effect and radiation protection developed in physics in parallel with the utilization of radiation. Although time, distance and shielding are the main rules to be protected from radiation, shielding is most effective way. In this case development of shielding materials becomes important. Clay is an interesting material and besides using it for different purposes it can be used as plaster material in building construction. In this study iron doped into clay samples and radiation shielding properties has been measured at $662 \mathrm{keV}$ gamma rays. The measurements have been performed using gamma spectrometer system which contains $\mathrm{NaI}(\mathrm{Tl})$ and $16 \mathrm{k}$ multichannel analyser.
\end{abstract}

DOI: 10.12693/APhysPolA.123.343

PACS: $29.30 . \mathrm{Kv}, 34.50 . \mathrm{Bw}$

\section{Introduction}

In recent years due to increasing use of radioactivity in medicine, the nuclear industry and in agriculture, etc., gamma-ray studies have attained a significant importance with the advancement of technology. There are three different manners to protect from radiation such as time, distance and shield [1-7]. Many researchers have study different types of shield material.

For this purpose, in this work, the photon attenuation coefficient of iron doped clay used in different rate has been measured at $662 \mathrm{keV}$ gamma rays.

\section{Materials and methods}

The iron was used in the rate of $5 \%, 10 \%, 15 \%, 20 \%$ and $30 \%$ in clay samples which are named as BD1, BD2, BD3, BD4 and BD5, respectively. The linear attenuation coefficients of iron doped clay samples were measured using the gamma spectrometer, contains a Canberra type $3^{\prime \prime} \times 3^{\prime \prime} \mathrm{NaI}(\mathrm{Tl})$ detector which is connected to the 16384 channels multi channel analyser (MCA). The communication of the system was performed using Genie2000 software $[4,7]$. A schematic view of the experimental system is given in Fig. 1.

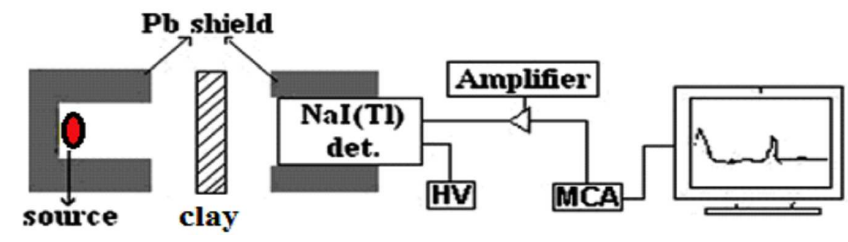

Fig. 1. A schematic view of the experimental system.

The linear attenuation coefficients have been evaluated comparing $N$ and $N_{0}$, which are the measured count rates in detector, with and without the absorber, respectively.

$$
\mu=\frac{1}{x} \ln \frac{N_{0}}{N}
$$

where $N$ is the number of counts recorded in the detector attenuation; $N_{0}$ is the number of counts recorded in the detector before attenuation; $\mu$ is the linear attenuation coefficient; $x$ is the thickness of the clay samples.

\section{Results and discussion}

In order to examine the effect of iron calculated photon attenuation coefficients, iron doped clays were compared with the previously measured boron doped clay [8]. As shown in Fig. 2, the boron doped clay is more effective shield radiation than iron doped clay.

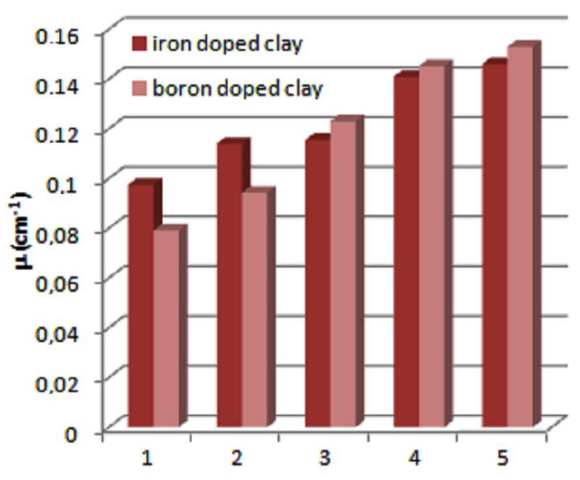

Fig. 2. Comparison of boron doped clay with iron doped clay.

Half-value thickness is the thickness of an absorber material that reduces the intensity of beam of gamma radiation to half its value. Half-value thickness is dependent on absorber material and photon energy of the radiation. 
The half value layer (HVL) and ten value layer (TVL), the linear attenuation coefficients were concluded using the following Eq. (2):

$$
\mathrm{HVL}=\frac{\ln 2}{\mu}, \quad \mathrm{TVL}=\frac{\ln 10}{\mu},
$$

where $\mu$ is the linear attenuation coefficient in $\mathrm{cm}^{-1}$. HVL is the thicknesses of an absorber that will reduce the radiation to half, and the TVL is the thicknesses of an absorber that will reduce the $\gamma$-radiation to tenth of its intensity.

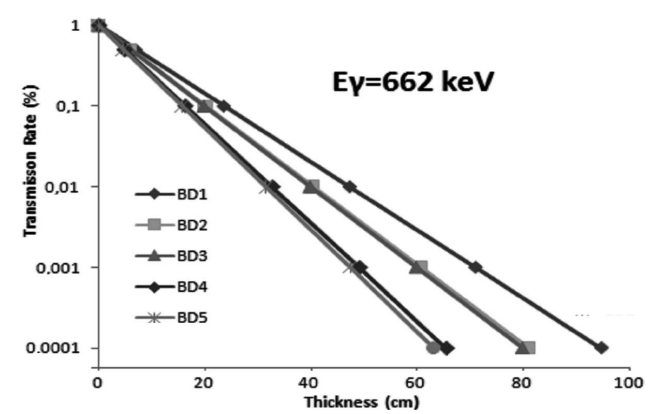

Fig. 3. Transmission rate of the iron doped clay for ${ }^{137} \mathrm{Cs}$.
The HVL and TVL are shown in Fig. 3. It can be seen that the HVL and TVL are bigger for low iron rate when compared with the high iron rate in clay.

\section{References}

[1] A.L. Conner, H.F. Atwater, E.H. Plassmann, J.H. McCrary, Phys. Rev. 1A, 539 (1970)

[2] I. Akkurt, B. Mavi, H. Akyıldırım, S. Kılıncarslan, C. Basyigit, Am. Inst. Phys. 978, 533 (2007)

[3] I. Akkurt, H. Akyıldırım, B. Mavi, S. Kılıncarslan, C. Basyigit, Ann. Nucl. En. 37, 910 (2010).

[4] B. Mavi, Ann. Nucl. En. 44, 22 (2012)

[5] A. Tomal, I. Mazarro, E.M. Kakuno, M.E. Poletti, Radiat. Measur. 45, 1055 (2010).

[6] F. Demir, Appl. Radiat. Isotopes 68, 175 (2010)

[7] I. Akkurt, R. Altindag, K. Günoğlu, H. Sarıkaya, Ann. Nucl. En. 43, 56 (2012)

[8] I. Akkurt, H. Canakci, Iran. J. Radiat. Res. 9, 37 (2011). 